\title{
Switching Transient Analysis and Characterization of GaN HEMT
}

Sun, Bainan; Zhang, Zhe; Andersen, Michael A. E.

Published in:

Proceedings of 3rd International Conference on Intelligent Green Building and Smart Grid

Publication date:

2018

Document Version

Peer reviewed version

Link back to DTU Orbit

Citation (APA):

Sun, B., Zhang, Z., \& Andersen, M. A. E. (2018). Switching Transient Analysis and Characterization of GaN HEMT. In Proceedings of 3rd International Conference on Intelligent Green Building and Smart Grid IEEE.

\section{General rights}

Copyright and moral rights for the publications made accessible in the public portal are retained by the authors and/or other copyright owners and it is a condition of accessing publications that users recognise and abide by the legal requirements associated with these rights.

- Users may download and print one copy of any publication from the public portal for the purpose of private study or research.

- You may not further distribute the material or use it for any profit-making activity or commercial gain

- You may freely distribute the URL identifying the publication in the public portal

If you believe that this document breaches copyright please contact us providing details, and we will remove access to the work immediately and investigate your claim 


\title{
Switching Transient Analysis and Characterization of GaN HEMT
}

\author{
Bainan Sun, Zhe Zhang, Michael A.E. Andersen \\ Dept. Electrical Engineering \\ Technical University of Denmark \\ Kongens Lyngby, Denmark \\ baisun@elektro.dtu.dk,zz@elektro.dtu.dk,ma@elektro.dtu.dk
}

\begin{abstract}
High electron mobility transistor (HEMT) has the advantage of fast switching capability, low power loss and small package design. Gallium Nitride (GaN) HEMT is widely researched in recent years. Accurate characterization and detailed switching analysis are critical for the practical application in power converters. In this paper, a $650 \mathrm{~V}$ GaN HEMT is tested based on the double pulse tester. Based on the experimental results, the switching transient analysis is given and the phenomenon of Miller plateau shifting is explained. Switching time and switching loss characterization are given as the reference value for converter design.
\end{abstract}

Keywords-double pulse test; GaN HEMT; Miller plateau; switching characterization

\section{INTRODUCTION}

As the development of Silicon semiconductors has reached its physical boundary, wide band-gap devices are considered as the next generation of semiconductor transistor [1]. GaN HEMT shows a promising potential in the fabrication of high frequency and high power density converter, which has been widely researched during the last decade [2], [3]. The basic structure of GaN HEMT can be plotted as the equivalent circuit shown in Fig. 1 [4].

Gating characterization and switching loss characterization are two major concern for the transistor application [5]. Gating characterization is decided by the transistor input capacitor $\left(C_{i s s}=C_{G S}+C_{G D}\right)$. Switching loss characterization is decided by the transistor output capacitor $\left(C_{o s s}=C_{D S}+C_{G D}\right)$ [6]. Benefit from wide semiconductor band-gap, GaN HEMT has a lower parasitic capacitor and lower conduction resistance than their Silicon counterparts, which leads to fast switching capability and low switching loss [7]-[9]. Accurate characterization of transistor switching loss and switching time is important for converter efficiency and modulation design. As a result, switching transient analysis of GaN HEMT is essential.

Double pulse test is a practical method for characterizing the transient performance of semiconductor transistor [10], [11]. Accuracy of the test result is highly dependent on the gate loop and power loop layout in the printed circuit board (PCB), as well as measurement technique [12]. Double pulse test has been carried out to characterize the switching loss of $\mathrm{GaN}$ HEMT [13], [14]. However, switching time characterization is not given. In addition, detailed analysis of the switching transient is absent.

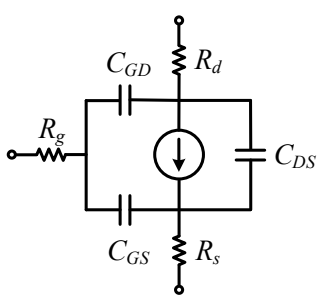

Fig. 1. Equivalent circuit of GaN transistor.

In this paper, double pulse test of $650 \mathrm{~V}$ GaN HEMT is carried out. Switching transient is analyzed and Miller plateau shifting phenomenon is explained. Switching loss and switching time characterization are given, which can be used as the reference value for converter design. The paper is arranged as follows: Section II introduces the double pulse tester design. Switching characterization and Miller plateau shifting phenomenon are explained in Section III. Section IV concludes the paper.

\section{Double Pulse Tester}

Equivalent circuit of double pulse tester is plotted in Fig. 2. GS66516B (e-mode, 650V) from GaN System is selected as the device under test. Among all these parasitic parameters, minimization of source inductance $\left(L_{s}\right)$ and gate inductance $\left(L_{g}\right)$ are the primary concern, which directly determines the transistor switching performance.

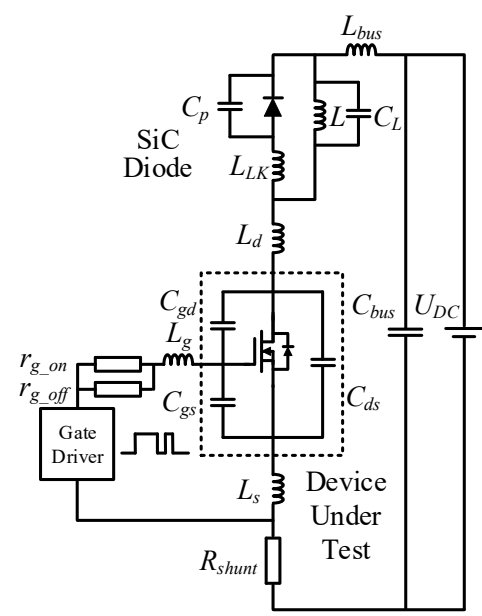

Fig. 2. Equivalent circuit of the double pulse tester. 
For GS66516B, Kelvin connection is adopted for the source pad design, which minimizes the $L_{s}$. For gate loop PCB design, special attention has been paid for the low impedance design, which minimizes the $L_{g}$. Operating principle of the double pulse test is shown as follows. Inductor $L$ is charged by the DC source when the transistor is gated on. The first pulse excites $L$ to a desired operating current and $\mathrm{SiC}$ Diode maintains the current flowing between the two pulses. The turn-on transient of the second pulse shares the same switching condition with the turn-off transient of the first pulse, which are thus used for switching characterization. Design method and measurement technique of the test are detailed as follows.

\section{A. Gate Loop Design}

Gate loop is the charging/discharging path of the transistor input capacitor, which directly determines the gate driving wave pattern. Gate resistors are generally installed to limit the gate charge/discharge current, which can be noted as (1), where $U_{g}$ is the on-state gate voltage and $U_{P L}$ is the voltage of Miller plateau. With a small gate resistance, large gate current can shorten the transistor switching transient, while, on the other hand, leads to extra ringing in the driving signal.

$$
I_{\text {charge }}=\frac{U_{g}-U_{P L}}{r_{g_{-} \text {on }}}, I_{\text {discharge }}=\frac{U_{P L}}{r_{g_{-} \text {off }}}
$$

The tolerance value of gate voltage is specified as $-10 \mathrm{~V}$ to $+7 \mathrm{~V}$ in the datasheet of GS66516B. Accordingly, a large gateon resistor is adopted for switching safety and a small gate-off resistor is adopted for fast switching off. Experimental results of the gate driver signal with different gate-off resistors are shown in Fig. 3. A large ringing in the gate-off signal can be observed when gate-off resistor is removed. The ringing spike may lead to false turn on during the switching off transient, which must be avoided in the application of power conversion. Gate resistor is selected as a tradeoff between switching time and gate signal ringing. When $r_{g_{\_} \circ n}=10 \Omega$ and $r_{g_{-} o f f}=2 \Omega$, the gate signal, shown in Fig. 3 , is ideal for switching application, which is adopted in the gate loop design.

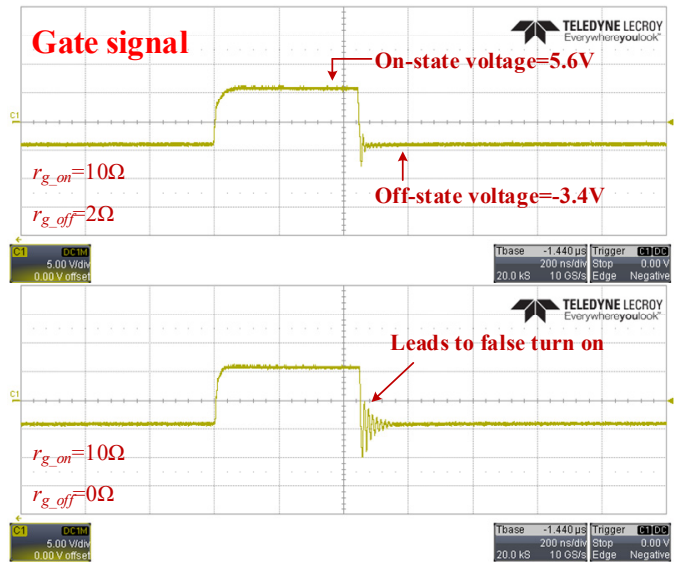

Fig. 3. Gate signal with different gate-off resistor.

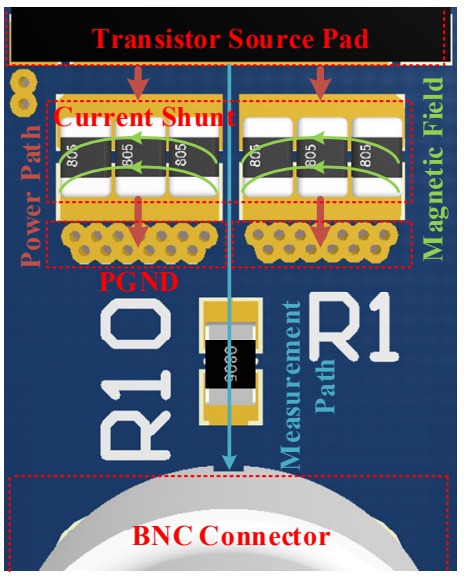

Fig. 4. PCB model of the current measurement method.

\section{B. Measurement Technique}

For transient analysis, wave pattern of $U_{d s}, I_{d}$ and $U_{g}$ during the switching process must be accurately measured. Since the bulky clamp can introduce large parasitic inductance into the transistor power loop, conventional current probe cannot be applied. A minimized stray inductance current shunt method is adopted in this paper, which is shown as the 3D PCB model in Fig. 4. Paralleled resistors are installed to the source pad of the transistor. The symmetrical arrangement results in the magnetic field cancellation and thus creates a current measurement path free from electric magnetic interference, which improves the measurement accuracy [15]. A low parasitic capacitance voltage probe $(7.5 \mathrm{pF})$ is adopted for voltage measurement and ground clip is utilized to minimize the ground inductance loop. Detailed test specification is elaborated in the next section.

\section{Double Pulse Tester}

The fabricated double pulse tester is shown in Fig. 5. Air core inductor is used for current forming. A C2000 launchpad board is used to generate the double pulse gate signal. At $400 \mathrm{~V}$ drain-source voltage, the transistor is driven from $5 \mathrm{~A}$ to 30A. Drain current is sampled according to the shunt voltage drop and picked up through $50 \Omega$ coaxial cable. Transient wave pattern and switching characterization are obtained.

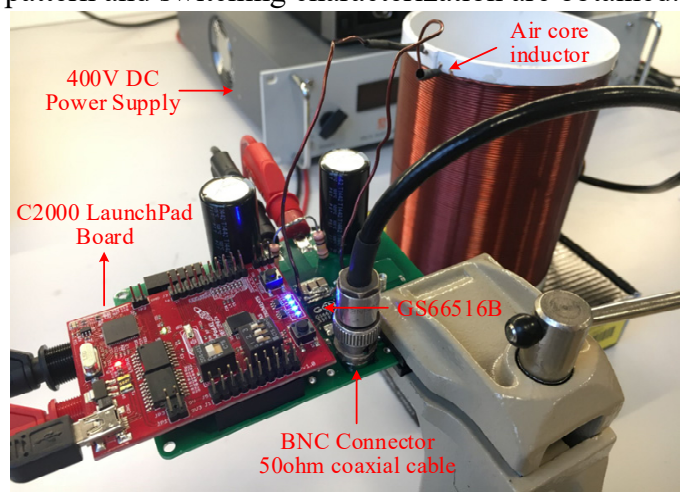

Fig. 5. Experiment set-up of double pulse tester. 


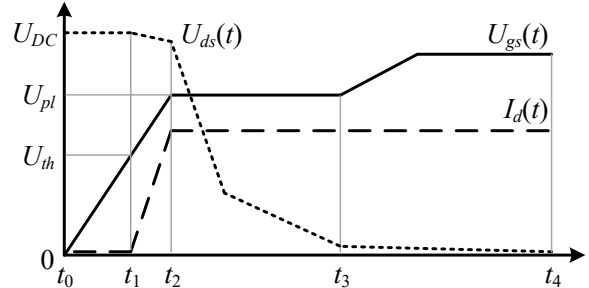

Fig. 6. Typical waveforms during transistor switch-on transient.

\section{SWTICHING CHARACTERIZATION}

Switching transient analysis is of vital importance for the performance evaluation of transistor. Typical waveforms during transistor switch-on transient is shown in Fig. 6. Gate current first charges the $C_{G S}$. As gate voltage reaches the threshold voltage $\left(U_{t h}\right)$, the transistor starts to partially gate on. During this period $\left(t_{1} \sim t_{2}\right)$, transistor current rises up to the load current until $C_{G S}$ is fully charged. After that, gate current starts to charge the $C_{G D}$, which is the well-known Miller plateau $\left(t_{2} \sim t_{3}\right)$. When $C_{G D}$ is fully charged, the gate voltage continues to rise until the on-state value $\left(t_{3} \sim t_{4}\right)$. After that, the transistor is fully gated on and switching transient is ended. The overlapping area of $U_{d s}(\mathrm{t})$ and $I_{d}(\mathrm{t})$ during $t_{1} \sim t_{3}$ can be calculated as the switch-on loss. The switch-off transient is symmetrical the reverse process. Experimental results based on the double pulse tester are given as follows.

\section{A. Switching Transient Analysis}

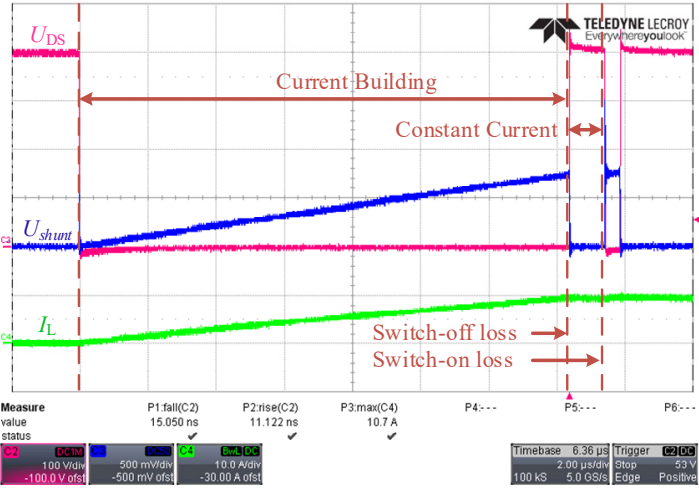

Fig. 7. Experimental waveforms of the double pulse test.

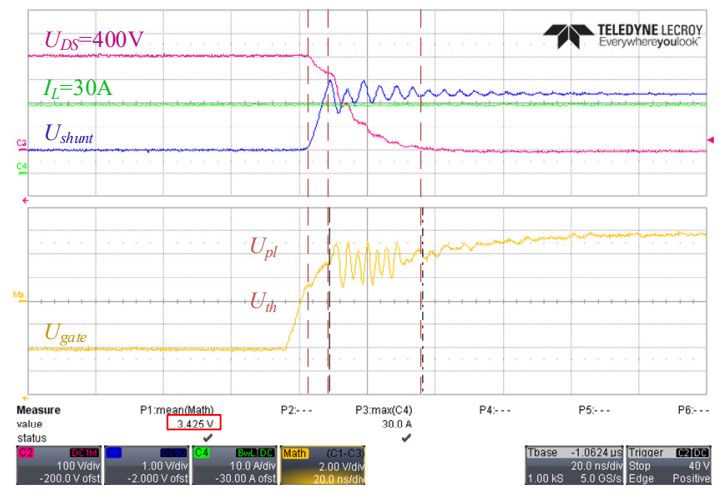

Fig. 8. Switch on transient at $400 \mathrm{~V}, 30 \mathrm{~A}$.
Experimental waveforms during the complete double pulse test is shown in Fig. 7. The first pulse gates on the transistor and charges the inductor to $10 \mathrm{~A}$. Inductor current is circuiting in the paralleled diode path and keeps constant during the interval between two gate pulses. The second pulse gates on the transistor again with the same switching condition. Switchon and switch-off performance are characterized at the marked transient point.

Experimental waveforms of the switch-on transient at $400 \mathrm{~V}$, $30 \mathrm{~A}$ is shown in Fig. 8. The waveforms are consistent with the theoretical analysis as well as the trend shown in Fig. 6. Switching transient is smooth, which validates the practical feasibility of the PCB layout design. Miller plateau voltage $\left(U_{p l}\right)$ is justified as $3.425 \mathrm{~V}$ at this switching condition, which is calculated according to the average value during the whole plateau interval. Threshold voltage is justified as $1.3 \mathrm{~V}$, which is consistent with the value specified in the transistor datasheet.

\section{B. Miller Plateau Shifting}

Double pulse test is carried out in a wide current range (from 5A to 30A). According to the experimental results, an obvious shifting of Miller plateau can be observed in the higher current rate. To validate the observation, value of Miller plateau voltage is recorded during the all the tests, which is shown in Table I. It can be concluded that the Miller plateau voltage is higher when GaN HEMT switches at a higher current rate. According to (1), a higher $U_{p l}$ will result in a lower gate-on current and higher gate-off current. As a result, characterization of the GaN HEMT gate-on and gate-off capability shall be different along different current rate. The switching time characterization of GS66516B is shown in Fig. 9. In a higher switching current, switch-on time is longer and switch-off time is shorter, which further validates the Miller plateau shifting phenomenon. It should be noted that the switch-off time at a lower current rate is much longer, which may interfere with the modulation scheme and leads to shootthrough in half bridge. Modulation dead time must be well designed in the application of power inversion, where current constantly crosses zero.

table I. Miller Plateau Voltage Characterization

\begin{tabular}{|c|c|c|c|c|c|c|}
\hline $\begin{array}{c}\text { Current Rate } \\
(\mathrm{A})\end{array}$ & 5 & 10 & 15 & 20 & 25 & 30 \\
\hline $\begin{array}{c}\text { Plateau Voltage } \\
(\mathrm{V})\end{array}$ & 2.90 & 3.05 & 3.22 & 3.29 & 3.35 & 3.43 \\
\hline
\end{tabular}

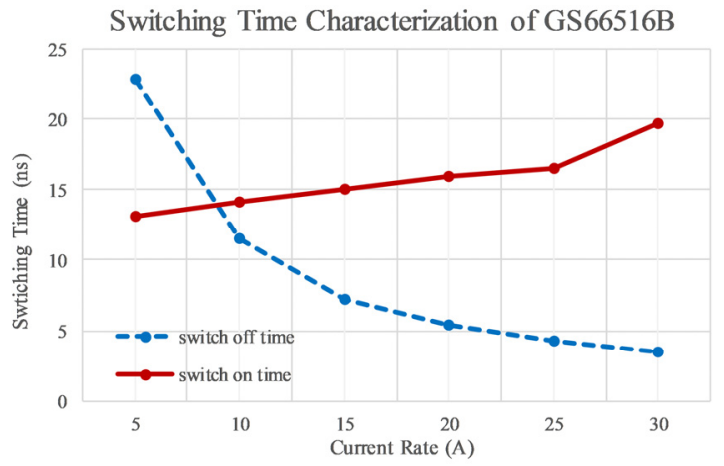

Fig. 9. Switching time characterization. 

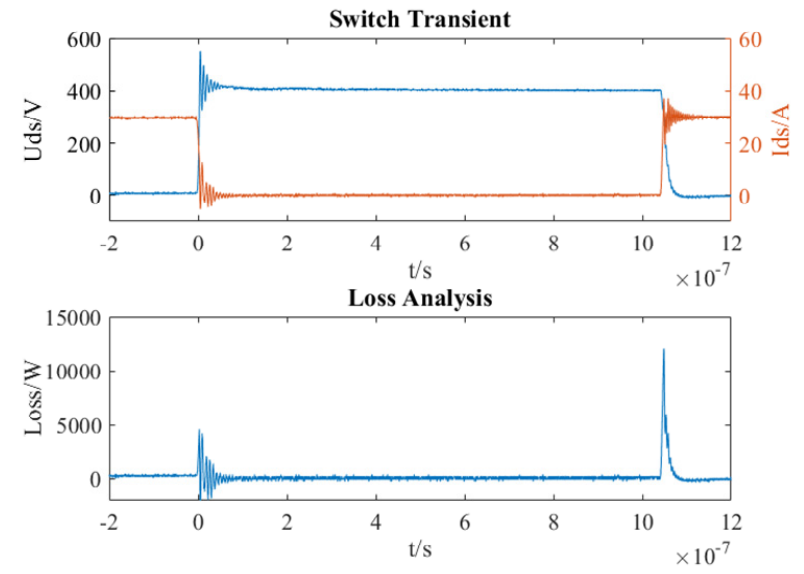

Fig. 10. Switching loss processed by MATLAB.

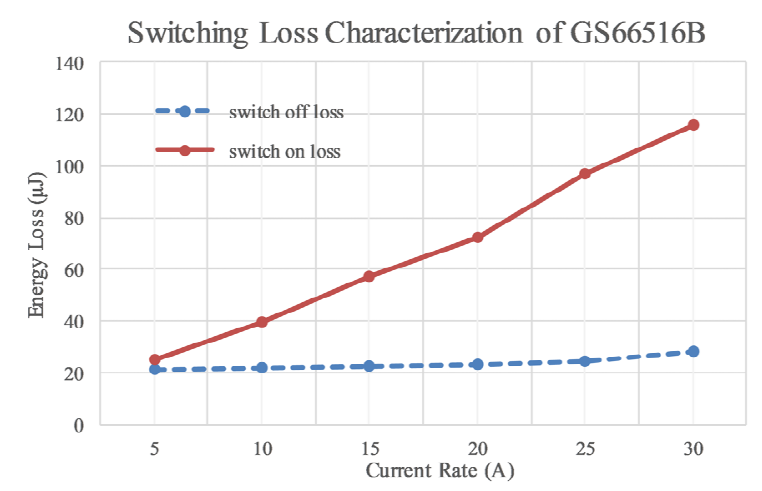

Fig. 11. Switching loss characterization.

\section{Swtiching Loss Characterization}

Switching loss is the main cause of converter power dissipation, especially in high frequency application. Accurate characterization of transistor is important for converter efficiency and heat sink design. Double pulse test results are processed with MATLAB to obtain the switching loss, which is shown in Fig. 10. $U_{d s}$ and $I_{d}$ are sampled in $10 \mathrm{~Gb} / \mathrm{s}$, and multiplied for instant power calculation. The instant loss power is integrated for $100 \mathrm{~ns}$ in the vicinity of each switching transient to obtain the switching loss. Switching loss characterization of GS66516B is shown in Fig. 11. Switch on and switch off loss both increase with a higher current rate. Switch on loss is the major part of loss dissipation, which indicates the necessity of soft-switching technique in the high frequency application.

\section{CONCLUSION}

In this paper, a double pulse tester is fabricated for $\mathrm{GaN}$ HEMT devices. Gate loop design and current measurement technique are elaborated. GS66516B, as a template, is tested and switching transient analysis is given. The phenomenon of Miller plateau shifting is introduced and validated by the switching time characterization. The switching loss characterization is given for converter design reference.

\section{REFERENCES}

[1] E. A. Jones, F. Wang, D. Costinett, Z. Zhang and B. Guo, "Cross conduction analysis for enhancement-mode $650-\mathrm{V}$ GaN HFETs in a phase-leg topology," 2015 IEEE 3rd Workshop on Wide Bandgap Power Devices and Applications (WiPDA), Blacksburg, VA, 2015, pp. 98-103.

[2] H. Wang, J. Wei, R. Xie, C. Liu, G. Tang and K. J. Chen, "Maximizing the Performance of $650-\mathrm{V}$ p-GaN Gate HEMTs: Dynamic RON Characterization and Circuit Design Considerations," in IEEE Transactions on Power Electronics, vol. 32, no. 7, pp. 5539-5549, July 2017.

[3] J. Lautner and B. Piepenbreier, "Analysis of GaN HEMT switching behavior," 2015 9th International Conference on Power Electronics and ECCE Asia (ICPE-ECCE Asia), Seoul, 2015, pp. 567-574.

[4] A. Lidow, J. Strydom, M. d. Rooij, and Y. Ma, GaN transistors for efficient power conversion: The eGaN FET journey continues, $1 \mathrm{st}$ ed. El Segundo and CA: Power Conversion Publications, 2012.

[5] M. Orabi and A. Shawky, "Proposed Switching Losses Model for Integrated Point-of-Load Synchronous Buck Converters," in IEEE Transactions on Power Electronics, vol. 30, no. 9, pp. 5136-5150, Sept. 2015.

[6] W. Eberle, Y. F. Liu and P. C. Sen, "A Resonant Gate Drive Circuit with Reduced MOSFET Switching and Gate Losses," IECON 2006 - 32nd Annual Conference on IEEE Industrial Electronics, Paris, 2006, pp. 1745-1750.

[7] T. Ishibashi et al., "Experimental Validation of Normally-On GaN HEMT and Its Gate Drive Circuit," in IEEE Transactions on Industry Applications, vol. 51, no. 3, pp. 2415-2422, May-June 2015.

[8] B. Sun, R. Burgos, X. Zhang and D. Boroyevich, "Active dv/dt control of $600 \mathrm{~V}$ GaN transistors," 2016 IEEE Energy Conversion Congress and Exposition (ECCE), Milwaukee, WI, 2016, pp. 1-8.

[9] K. Kruse, M. Elbo and Z. Zhang, "GaN-based high efficiency bidirectional DC-DC converter with $10 \mathrm{MHz}$ switching frequency," 2017 IEEE Applied Power Electronics Conference and Exposition (APEC), Tampa, FL, 2017, pp. 273-278.

[10] J. C. Hernandez, L. P. Petersen and M. A. E. Andersen, "Characterization and evaluation of $600 \mathrm{~V}$ range devices for active power factor correction in boundary and continuous conduction modes," 2015 IEEE Applied Power Electronics Conference and Exposition (APEC), Charlotte, NC, 2015, pp. 1911-1916.

[11] P. Tu, P. Wang, X. Hu, C. Qi, S. Yin and M. A. Zagrodnik, "Analytical evaluation of IGBT turn-on loss with double pulse testing," 2016 IEEE 11th Conference on Industrial Electronics and Applications (ICIEA), Hefei, 2016, pp. 963-968.

[12] H. Peng, R. Ramabhadran, R. Thomas and M. J. Schutten, "Comprehensive switching behavior characterization of high speed Gallium Nitride E-HEMT with ultra-low loop inductance," 2017 IEEE 5th Workshop on Wide Bandgap Power Devices and Applications (WiPDA), Albuquerque, NM, 2017, pp. 116-121.

[13] M. Danilovic, Z. Chen, R. Wang, F. Luo, D. Boroyevich and P. Mattavelli, "Evaluation of the switching characteristics of a galliumnitride transistor," 2011 IEEE Energy Conversion Congress and Exposition, Phoenix, AZ, 2011, pp. 2681-2688.

[14] Z. Liu, X. Huang, F. C. Lee and Q. Li, "Package Parasitic Inductance Extraction and Simulation Model Development for the High-Voltage Cascode GaN HEMT," in IEEE Transactions on Power Electronics, vol. 29, no. 4, pp. 1977-1985, April 2014.

[15] A. Anthon, J. C. Hernandez, Z. Zhang and M. A. E. Andersen, "Switching investigations on a SiC MOSFET in a TO-247 package," IECON 2014 - 40th Annual Conference of the IEEE Industrial Electronics Society, Dallas, TX, 2014, pp. 1854-1860. 